controlled trials tend to report data only on short term effects, while extended follow-up of long-term mortality data of treatment strategies are scarce.

Objectives: To compare mortality risk over up to 14 years of follow-up in MTX-refractory patients with early RA, randomized to a strategy starting with addition of infliximab versus addition of sulfasalazine and hydroxychloroquine.

Methods: We used data from a 2-arm, parallel, randomized, active-controlled, open-label trial (Swefot), in which patients with early RA (symptom duration <1y) were recruited from 15 rheumatology clinics in Sweden from 2002-2006. Patients who did not achieve low disease activity after 3-4 months of MTX were randomized to receive additional biological treatment with infliximab $(\mathrm{n}=128)$ or conventional combination treatment with sulfasalazine and hydroxychloroquine $(n=130)$. By linking the trial database to the Swedish Total Population Register and Cause of Death Register, we collected complete data on all-cause mortality and emigration until August 31, 2017. Participants were followed until death, emigration, or end of followup, whichever came first. Analyses were by intention to treat.

Results: Over a total 1477 and 1504 person-years of follow-up in the infliximab and the conventional combination treatment group there were 13 and 16 deaths, respectively $(8.8[95 \% \mathrm{Cl} 0.0-25.1]$ versus $10.6[95 \% \mathrm{Cl}$ 0.0-28.4] deaths per 1000 person-years; mortality hazard ratio 1.2 [0.62.5]; $\mathrm{P}=0.62$; Figure). After 5 years, approximately $50 \%$ of patients in the infliximab arm remained on biologic therapy and $50 \%$ in the conventional combination arm remained on synthetic DMARDs.

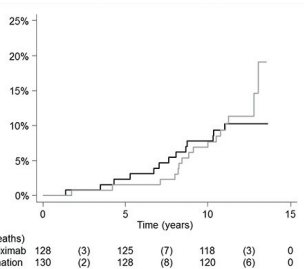

Abstract THU0090 - Figure 1. Cumulative incidence of death over up to 14 years of followup in the Swefot trial in patients with early RA with an insufficient response to MTX, randomized to a strategy starting with addition of either infliximab or conventional combination DMARD treatment.

Conclusion: No increased or decreased mortality risk could be observed over up to 14 years of follow-up in patients with MTX-refractory early RA, randomized to a strategy starting with addition of infliximab compared to patients randomized to a strategy starting with conventional combination treatment. At the end of the extended follow-up, a minority of patients remained on their assigned therapy, reflecting the treat to target paradigm. Disclosure of Interests: Heather Miller: None declared, Johan K Wallman Consultant for: Consultant for AbbVie, Celgene, Eli Lilly, Novartis, and UCB Pharma., Ingemar Petersson: None declared, Saedis Saevarsdottir Employee of: Part-time employee at deCODE Genetics/Amgen Inc, working on genetic research unrelated to this project., Jonas Söderling Consultant for: Abbvie, Merck, Novartis, Pfizer and Shire (unrelated to the present work), Sofia Ernestam: None declared, Johan Askling Grant/research support from: Karolinska Institutet (JA) has or has had research agreements with the following pharmaceutical companies, mainly in the context of the ATRIS national safety monitoring programme for rheumatology biologicals: Abbvie, BMS, MSD, Eli Lilly, Pfizer, Roche, Samsung Bioepis, and UCB., Consultant for: Karolinska Institutet has received remuneration for JA participating in ad boards arranged by Lilly, Novartis, and Pfizer., Ronald van Vollenhoven Grant/research support from: AbbVie, BMS, GSK, Pfizer, UCB, Consultant for: AbbVie, AstraZeneca, Biogen, Biotest, BMS, Celgene, Gilead, GSK, Janssen, Lilly, Novartis, Pfizer, UCB, Speakers bureau: AbbVie, Lilly, Pfizer, UCB, Martin Neovius: None declared

DOI: 10.1136/annrheumdis-2019-eular.4034

\section{THU0091 \\ DEPRESSION IN PATIENTS WITH RHEUMATOID ARTHRITIS: UNDER RECOGNIZED, UNDERTREATED AND ASSOCIATED WITH POORER CLINICAL STATUS AND LOWER RATES OF REMISSION IN ROUTINE CARE}

Rosa Morla ${ }^{1}$, Mariam Riad ${ }^{2}$, Theodore Pincus ${ }^{2}$, Isabel Castrejon ${ }^{2} .{ }^{1}$ Fundació Clínic, Barcelona, Spain; ${ }^{2}$ Rush University Medical Center, Chicago, United States of America

Background: Depression in patients with rheumatoid arthritis (RA) may be pre-existent, amplified, or newly-developed after onset of RA. Together with other comorbidities, socioeconomic, or affective factors can influence perception of pain, functional disability, and health status. The prevalence of depression in RA patients is $19 \%$ and affect remission rates according to a classical composite index. ${ }^{1}$

Objectives: We compared patient self-reported scores included on the Multidimensional Health-Assessment Questionnaire (MDHAQ) and levels of remission according to RAPID3 in patients who self-reported depression versus no depression.

Methods: All patients complete a MDHAQ at each visit, which includes physical function (FN), three 0-10 visual analogue scales (VAS) for pain (PN), patient global estimate (PATGL), fatigue (FT), RADAl self-report joint count, a review of 60 symptoms (ROS) on a checklist, three evaluations for depression, anxiety and sleep quality (0-3.3), and demographics. RAPID3 (0-30) is the sum of FN, PN, and PATGL; being remission RAPID3 <3. Patients with RA (ICD10) were classified according to selfreported depression on the ROS. Agreement between MDHAQ-depression and by the Patient Health Questionnaire (PHQ-9) was evaluated in 57 patients. Demographic and clinical characteristics were compared by selfreported depression status using Student t-test and chi-square test.

Results: 464 RA patients were studied: 118 (25\%) self-reported depres sion. In 57 patients, who also completed the PDQ-9, agreement with MDHAQ depression was 93\% (kappa=0.80 95\% IC 0.61-0.99). Only 37 $(31 \%)$ of all patients reporting depression had evidence in the medica record of treatment and/or specialist evaluation for depression. No differences between depression groups were seen for mean age or sex Patients reporting depression had lower education level (12.5 vs 14.3 $\mathrm{p}<0.001$ ) and poorer scores for physical function, pain, and patient global leading to higher RAPID3 and lower percentage of patient in remission (12.4 vs $4 \%, p<0.001$ ) (Table). Depressed patients also reported higher scores for fatigue, number of painful joints, number or symptoms, and more difficulty with sleep, and anxiety.

Table: MDHAQ patient self-report scores in patients with RA according to depression status. Data are presented as mean (SD) and percentages. ${ }^{*} \mathrm{p}<0.001$

\begin{tabular}{lcc}
\hline & $\begin{array}{c}\text { No self-reported depression } \\
\mathrm{N}=346(75 \%)\end{array}$ & $\begin{array}{c}\text { Self-reported } \\
\text { depression } \\
\mathrm{N}=118(25 \%)\end{array}$ \\
\hline Demographic variables & $55.4(14.9)$ & $55.8(15.1)$ \\
\hline Age, years & $84 \%$ & $91 \%$ \\
Female,\% & $14.3(3.1)$ & $12.5(3.4)^{\star}$ \\
Education level, years & & \\
MDHAQ/RAPID3: Patient self-report scores & $2.4(2.0)$ & $3.4(1.9)^{\star}$ \\
Physical function (0-10) & $5.3(3.0)$ & $6.8(2.6)^{\star}$ \\
Pain (0-10) & $4.9(3.0)$ & $6.6(2.7)^{\star}$ \\
Patient global estimate (0-10) & $12.6(7.2)$ & $16.6(6.4)^{\star}$ \\
RAPID3 (0-30) & $12.4 \%$ & $4 \% \%^{*}$ \\
\% patients in RAPID3 remission & $4.2(3.2)$ & $6.3(3.0)^{\star}$ \\
Fatigue (0-10) & $12(10)$ & $18(12)^{*}$ \\
Self-reported joint pain-RADAI (0-48) & $8(7)$ & $18(9)^{*}$ \\
Review of Symptoms (0-60) & $1.1(0.9)$ & $1.9(0.9)^{\star}$ \\
Sleep problems (0-3.3) & $1.1(0.9)$ & $1.9(0.9)^{*}$ \\
Dealing with depression/feeling blue (0-3.3) & $0.1(0.4)$ & $0.7(0.4)^{\star}$ \\
Dealing with anxiety/being nervous (0-3.3) & &
\end{tabular}

Conclusion: The prevalence of self-reported depression in our RA patients was $25 \%$, with only $31 \%$ treated for this condition. RA patients with self-reported depression exhibit higher scores for all MDHAQ scores, and a lower rate of RAPID3 remission. MDHAQ may be useful to identify patients with depression in busy clinical settings.

\section{REFERENCE:}

[1] Leblanc-Trudeau, C, et al. Rheumatology 2015;54:2205-14. 